\title{
INVESTIGAÇÃO EM SERVIÇOS DE SAÚDE: QUAL É O SEU PROBLEMA?*
}

José da Rocha Carvalheiro**

Resumo: 0 Autor relata experiências que acompanhou nas duas últimas décadas, relacionadas com a Investigação de Serviços (e Sistemas) de Saúde (ISS). Partindo da diversidade da abrangência do objeto desse campo da pesquisa, segundo se depreende da temática de vários seminários realizados na América Latina, faz uma incursão pela definição operacional de ISS e as categorias de estudos que pode incluir. Retoma a discussão da questão epistemológica, colocada no nivel do reconhecimento da importância do saber de senso comum produzido no cotidiano dos serviços de saúde. Conclui propondo abordagem que incorpore três aspectos essenciais: a moderna Teoria das Redes na gênese e circulação dos fatos científicos (CALLON, 1989); as Matrizes de Dados e o nivel de ancoragem (SAMAJA, 1995); o Postulado de Coerência e a questão do Poder (TESTA, 1992).

\section{A ESTATÍSTICA APELA A KARL MARX}

O celebrado estatístico Norman Bailey inicia o capitulo de um de seus livros (BAILEY, 1977) com citação, no original alemão, da undécima tese contra Feuerbach, de Karl Marx: "os filosofos se limitaram a interpretar o mundo diferentemente, cabe transformá-1o". O inusitado encontro desta referência num livro de estatística, baseado em obra do mesmo autor publicada dez anos antes (BAILEY, 1967), explica-se pelo complemento do título: "Matemática, Estatística e

\footnotetext{
- Financiamento CNPq

"* Professor Titular. Departamento de Medicina Social Faculdade de Medicina de Ribeirão Preto. USP. Diretor do Instituto de Saúde. SES/SP.
} 
Sistemas para a Saúde". Não deve ter sido ocasional a escolha do capitulo onde o autor insere a citação. Existe um capitulo sobre Pesquisa Operacional, mas a citação encontra-se num outro, destinado à discussão sobre Equipes, Projetos e Organizações.

Ao abordar a pesquisa operacional, Bailey parte da tradicional dicotomia entre ciência pura e aplicada. Reconhecendo não haver linha demarcatória nítida, acredita ser "genericamente verdadeiro afirmar que a ciência pura preocupa-se essencialmente com a compreensão de fenômenos fundamentais, enquanto a ciência aplicada ocupa-se com a utilização prática deste conhecimento para controlar e manipular nosso ambiente". Adota como definição para pesquisa operacional: "o estudo científico de problemas executivos ou administrativos" e acrescenta ser ela "certamente muito valiosa para sublinhar diferenças importantes entre a ciência pura e a aplicada".

Esta extensa citação do estatístico Bailey, na época pertencente aos quadros da OMS, na Unidade de Metodologia Estatística em Saúde, tem sua razão. Passados praticamente vinte anos da publicação de seu livro, é evidente que algumas afirmações tiveram caráter quase premonitório. Talvez a principal seja a identificação da vertiginosa rapidez com que se "colecionavam atividades cientificamente orientadas e mais preocupadas com as formas de organização do que com a matéria concreta que se estava organizando". Concluia, afirmando que "problemas administrativos e executivos tendem a ter muito em comum, seja qual for seu objetivo concreto". Não surpreende, portanto, a simplicidade como no Brasil atual altos executivos mudam tão rapidamente de ministérios e secretarias de Estado. Dormem especialistas em transporte coletivo, acordam na saúde.

No capitulo sobre Equipes, Projetos e Organizações, Bailey preconiza a necessidade de transformação do mundo e dá as pistas. Obviamente inclui a 
universidade em seu múltiplo papel de instituição destinada ao ensino, à pesquisa e à extensão. Esta última, concebida tanto como trabalho em conjunto quanto como produção de "livros de receitas de técnicas tornadas disponíveis para uso rotineiro como qualquer outra peça de equipamento científico". Após passar pelo trabalho cooperativo, o autor sente-se na obrigação de afirmar, mencionando a área da saúde, que "quanto mais elevado o posto ocupado na hierarquia administrativa tanto mais seu ocupante estará potencialmente envolvido com esferas de pesquisa operacional, análise e dinâmica de sistemas, análise de políticas". É interessante mencionar que, na época, o autor vivia na OMS um momento dos mais importantes: a Assembléia Mundial já aprovara o compromisso de Saúde Para Todos até o Ano 2000 (SPT/2000) e buscava caminhos para saldá-lo. O mundo ansiava por transformações, como no tempo de Karl Marx. Ao invés da $1^{a}$ Internacional, a OMS criou no ano seguinte, em Alma Ata no Casaquistão, o Movimento da Atenção Primária em Saúde (APS) (WHO, 1978). A "Declaração de Alma Ata" é 130 anos posterior ao "Manifesto Comunista". A luta pelo socialismo deu no que se viu na década passada, triste prenúncio para esta proposta de eqüidade em saúde. Uma nova utopia?

\section{ATENÇÃO PRIMÁRIA SAÚDA AS AUTORIDADES}

\section{E PEDE PASSAGEM PARA ISS}

O que já foi escrito a respeito da SPT/2000 e da APS nos últimos vinte anos, reciclado o papel e transformado em absorvente, daria para enxugar os sete mares. Vendo aproximar-se o ano 2000 , seria o caso de perguntar em que dia se alcançará a SPT. Talvez num dia primeiro, calendas romanas. É mais prudente pensar nas calendas gregas, inexistentes como é domínio público. Comentando o 
pensamento de Ortega y Gasset já se disse ser antiutópico e anticalendas gregas*. Parece que falavam da SPT/2000.

Grande parte dessa imensa quantidade de resmas de papel destinou-se à epidemiologia, ao planejamento e a outras maneiras tidas como mágicas suficientes para alcançar a SPT/2000. Nos últimos tempos ganhou relevância a Investigação em Serviços de Saúde (ISS). Onde falharam epidemiologia e planejamento, a ISS não falhará. Introduzida na prática dos serviços, em todos os niveis, servirá aos dirigentes como o mais eficaz instrumento de ação decisória. Tratando-se de pessoas muito ocupadas, tanto mais quanto mais elevadas na hierarquia, não terão tempo para ler extensos trabalhos cientificos. Nem jomais conseguem ler, valendo-se de excertos ("clippings") elaborados por assessores de imprensa. Vamos pois inventar um moderno meio de comunicação com os dirigentes. Já que o seu contato com a realidade social é filtrado da imprensa através de "clippings", a realidade científica deve criar ○ seu. Investigaçōes simplificadas, difundidas por toda a estrutura da rede de serviços, deveriam encaminhar aos dirigentes, do nivel respectivo, sumários executivos contendo os elementos essenciais para tomada de decisões. Estimativas rápidas detectam necessidades "tecnicamente" definidas que grupos focais, compostos por lideranças da comunidade, transformam em problemas. Em se considerando incapaz de resolvê-los por via administrativa, o dirigente encomenda proposta de solução, através de uma ISS que produza um sumário executivo.

Esta proposta simplista causa arrepios na espinha da maioria dos estudiosos da área da metodologia cientifica, inclusive dos colaboradores deste número especial de Saúde e Sociedade. Viola completamente tudo o que se tem avançado na discussão das encomendas sociais, legitimadoras do trabalho do pesquisador gerado no processo de divisão sócio-técnica do trabalho (BRUYNE et

\footnotetext{
"in "El Espectador-Revista de Occidente". V-VI, p1 14. Madrid. 1961.
} 
al, 1982). Ou, usando os conceitos de GARCIA (1981), promove uma contrafacção da determinação social dos interrogantes da pesquisa, conseguindo a objetivação dos problemas através de verdadeiras "receitas de bolo", sem nenhuma sofisticação metodológica e difundidas através de manuais. Como se a ciência pudesse ser assim banalizada. É bom assinalar, no entanto, que o já mencionado BAILEY (1977) inclui a produção destes manuais como tarefa de extensão universitária.

Numa revista com a proposta de Saúde e Sociedade, simultaneamente comprometida com a academia e com os serviços, deveria ser iniciado um debate que contemplasse todos os ângulos desta polêmica. Considerando a abordagem de BRUYNE et al(1982), não podemos travar a discussão exclusivamente no campo da cientificidade do conhecimento (epistêmico). Permanece aberta a discussão no campo da demanda social, da formulação dos interrogantes; no campo dos valores sociais que condicionam a pesquisa (axiológico) e no campo do saber não sistematizado, da linguagem e das evidências da prática quotidiana (doxológico).

Nesta contribuição pretendo, apenas com o intuito de iniciar o debate, relatar algumas experiências vividas nos últimos quinze anos e relacionadas com a ISS. Esse relato será acompanhado de algumas reflexões que me ocorreram na época. Reservo para outro momento uma análise mais minuciosa, especialmente considerando a identificação dos problemas e a proposta metodológica para o encontro de soluções. 


\section{A ISS TAL COMO A VI E VIVI*}

Pelo menos desde o início da década de 70 , tenho participado de investigações sobre Serviços de Saúde. A montagem de um sistema de amostragem continua, em Ribeirão Preto, para análise de condições de saúde e consumo de serviços (CARVALHEIRO, 1975) é o marco zero, mas há uma préhistória. Nesse trabalho estão referidas suas raizes, nos anos iniciais da década, num Distrito (Guatapará) e num Bairro (Vila Lobato) da cidade. Diversos trabalhos publicados e teses orientadas, continuaram no mesmo sentido. Tratava-se, no entanto, de reflexões sobre os serviços. Apesar de todo o esforço, uma visão do exterior, da academia.

Em diversas reuniōes sobre ISS, no Brasil e no exterior, verifico que os limites da Investigação em Sistemas e Serviços de Saúde têm variado conforme o objetivo das reuniōes. Num limite extremo, os conceitos de investigação em saúde e investigação em sistemas e serviços de saúde tornam-se idênticos, podendo incluir qualquer tipo de investigação na área de saúde. Num outro extremo, delimita-se o papel da investigação à utilização do método científico para avaliação de problemas de maior simplicidade, o que a torna passivel de ser realizada nos serviços, pelo pessoal do serviço.

Tomo, como exemplo, diversos seminários que foram realizados nas últimas décadas e nos quais tive participação, direta ou próxima. Em 1978, em seminário realizado no México, foi analisada a situação da Investigação em Serviços de Saúde no México, na Inglaterra e nos Estados Unidos da América, centrando-se na qualidade da atenção médica. Deste, não participei diretamente. Apenas o menciono como contraponto, que pode ser melhor ajuizado pelos

\footnotetext{
* Foi aproveitado, em parte, resumo da intervenção do Autor no Seminário realizado na ENSP em abril de 1994, citado na Bibliografia como NORONHA \& GAWRYSZEWSKI (1994).
} 
conferencistas principais: Barr, Rosenthal, Knox, Laguna e Donabedian (CONACYT, 1979).

Em 1984, também no México, em Cocoyoc (Morelos), foi realizado outro seminário em que foram apresentados os resultados de um levantamento sobre a situação da Investigação em Serviços de Saúde na América Latina e, a partir dai, realizadas reflexões acerca dos rumos da investigação nessa área. Foi adotada uma definição mais ampla de investigação em serviços de saúde. Este seminário, em sua concepção, representa o último legado em vida de Juan Cesar Garcia à Saúde Coletiva na América Latina. Todo o esforço de organização foi coordenado, de Washington, pelo Escritório Central da OPAS/OMS. Dirigido, na fase de execução, por Luis Jorge Osuna, contou com a presença do Diretor da OPAS, Carlyle Guerra de Macedo, e de vários dirigentes da academia e dos serviços do México. Iniciou-se com um longo e demorado trabalho de levantamento, em 15 países, do campo de investigação em serviços nos últimos dez anos (1974-1983). No Brasil, o estudo foi coordenado por Eurivaldo Sampaio de Almeida, da Faculdade de Saúde Pública da USP (ALMEIDA, 1984). Foram entrevistados pesquisadores e dirigentes da área de saúde em todos os países (Argentina, Barbados, Bolivia, Brasil, Chile, Colômbia, Costa Rica, Cuba, Equador, Jamaica, México, Peru, Trinidad-Tobago, Uruguai e Venezuela). Os resultados foram analisados e apresentados por um grupo de pesquisadores recrutados pela OPAS/OMS entre os responsáveis pelos estudos nacionais (GOMES COVA, ALMEIDA \& VARGAS, 1984). Durante o seminário, além das discussões de grupo, foram pronunciadas três conferências temáticas abordando aspectos metodológicos (APEZECHEA, 1984) e práticos (CARVALHEIRO, 1984; YEPEZ, 1984). Pelo conteúdo do resultado final, especialmente no que diz respeito à delimitação do campo da ISS, considero ser este o esforço mais sério dentre todos os que acompanhei, no período. 
Já na apresentação do coordenador do seminário (OSUNA, 1984) são dadas as diretrizes básicas. Não se trata de reabrir a polêmica estéril entre pesquisa básica, aplicada e de desenvolvimento. Trata-se, isto sim de um "esforço consciente para ordenar a grande riqueza do conhecimento sobre distintos processos que intervêm na prestação de serviços, amplificados pela aceleração das mudanças no entorno social". Adotou-se uma definição operacional de ISS e uma classificação dos estudos em nove categorias, ambas adaptadas de documentos da OMS que, a meu juizo, seguem vigendo.

ISS: estudo sistemático dos meios pelos quais o conhecimento médico básico e outros conhecimentos relevantes se aplicam à saúde dos individuos e da comunidade, sob um conjunto dado de condições existentes.

Categorias de estudos:*

1. Relaçōes dos serviços com o entorno social - $289(10,0 \%)$

2. Determinaçáo das necessidades e demandas de saúde da população - 906 (31,2\%)

3. Produção e distribuição de recursos - 345 (11,9\%)

4. Estrutura organizativa e componentes do sistema de saúde - 199 (6,9\%)

5. Estudo da utilização de serviços de saúde - $512(17,7 \%)$

6. Administraçáo dos Serviços de Saúde - 241 (8,3\%)

7. Análise económica - 74 (2,6\%)

8. Avaliação de Programas - 292 (10,1\%)

9. Participação da comunidade em sua relação com os serviços de saúde - 41 (1,4\%)

A partir daí, talvez em parte pelo prematuro desaparecimento de Juan Cesar Garcia, os esforços neste domínio mais conceitual se abrandaram. Devem ser mencionadas, no entanto, algumas iniciativas da própria OPAS/OMS que redundaram em documentos de trabalho de circulação mais ou menos restrita (OPS, 1987). Destes esforços resultaram contribuições que incluíram a temática da ISS em publicação relacionada com os Sistemas Locais de Saúde (SONIS, 1990; CHORNY et. al., 1990). Um documento mais alentado, fruto de um trabalho de compilação internacional de 100 artigos sobre o tema, foi publicado também pela OPS (1992). Este documento recebeu várias críticas quanto ao seu conteúdo. A principal delas circulou em mimeografado de NAVARRO(1992). Criticava,

\footnotetext{
"Os números se referem aos trabalhos analisados no levantamento da América Latina (total=2899).
} 
especialmente, o viés metodológico da coletânea que, a seu ver, excluia toda a contribuição recente dos grupos mais criativos da América Latina, num evidente patrulhamento epistemológıco. Queixava-se da exclusão de contribuições originais em língua espanhola e da excessiva importância que os autores da coletânea atribuiram a seus próprios trabalhos. É ocioso acrescentar que Navarro, autor de contribuições importantes, em inglês no original, não figura na coletânea. Ironicamente, em seus queixumes em nome dos excluidos, ignorou, também ele, a importante contribuição, em língua portuguesa, de autores brasileiros. É nosso dever assinalar que figuram na coletânea diversos trabalhos da América Latina, dois deles de autores brasileiros (YAZZLE ROCHA et al, 1985; BARROS et al, 1986).

Nos últimos anos, ganha destaque a iniciativa coordenada pela OMS, Genebra, destinada a incluir a pesquisa sobre sistemas de saúde na discussão do desenvolvimento e. em particular da estratégia para alcançar a SPT/2000 (WHO, 1990). Baseia-se na idéia de uma pesquisa orientada para a ação, instrumento para tomada de açōes gerenciais. Este é o principal tema de discussão na área, no atual momento. Os esforços da OMS estão respaldados por diversas fundações intemacionais, atuando, na América Latina, especialmente o IDRC* , do Canadá.

Em 1991, novamente no México, em Xalapa (Veracruz), foi realizado um seminário onde foram apresentados os resultados de investigaçōes realizadas a partir desta nova vertente proposta pela OMS, de treinamento em metodologia de investigação para pessoal dos serviços de saúde. Este seminário teve características que diferenciavam a nova proposta de investigação em sistemas de saúde das propostas mais abrangentes que haviam circulado pela América Latina até então. Caracteriza-se a nova proposta pela introdução do Sumário Executivo:

\footnotetext{
- International Development Research Center.
} 
numa linguagem simples, dos objetivos da pesquisa, dos resultados encontrados e as recomendações para o nível gestor do serviço.

A idéia central é a da produção de uma proposta metodológica simples e objetiva que permita abordar problemas mais simples, sem a exigência de originalidade. São obtidos resultados às vezes já conhecidos de longa data pelo meio científico. Porém, emprega-se a metodologia apropriada para enfrentar um problema concreto e não aquele genérico já analisado exaustivamente. Tudo isso, entretanto, pode representar uma contrafacção, pelas recomendações pouco apropriadas que eventualmente aparecem. No mesmo seminário foi distribuído material produzido anteriormente (INSP, 1991), abordando treze diferentes problemas. O enunciado desses problemas nos dá uma idéia do âmbito das preocupações:

Problemas:

1. A desigualdade da qualidade na atenção médica em diferentes instituiçర̃es.

2. Magnitude e conseqüências do desemprego médico.

3. A incapacidade do sistema de saúde atual para responder a mudanças epidemiológicas.

4. Padroes reprodutivos que elevam o risco de morte infantil.

5. O sub-registro crescente da mortalidade infantil.

6. Os fatores sociais e culturais na utilização de serviços.

7. A alta prevaléncia dos fatores associados com o baixo peso ao nascer.

8. A elevada freqüéncia de cesáreas no Distrito Federal (México): seus efeitos sobre a saúde perinatal.

9. A baixa cobertura regional dos serviços de atenção para população aberta.

10. A iniqüidade e ineficácia do sistema de cotas de recuperação (versão mexicana do "fator moderador" cobrado do usuário segundo nível sócio-económico).

11. A baixa qualidade da atençăo médica no primeiro nível.

12. Desconhecimento da Lista Básica de Medicamentos no primeiro nível de atençåo.

13. A qualidade de atençăo médica no primeiro nível de atenção da Secretaria de Saúde.

Não se trata, como se vê, de problemas tão simples, de nível local ou de serviços periféricos. Apenas para ilustrar a já mencionada inadequação de algumas recomendações ("possiveis soluções", no original):

Problema 1:"modificar o modelo vigente de atenção ao parto"

6:"produzir mudança de mentalidade nos profissionais de saúde"

7:"promover a nutriçăo adequada da mulher, em todas as etapas da vida" 
11:"mudar a concepção de saúde e doença que prevalece na população"

No seminário de Xalapa propriamente dito, os problemas analisados eram, em geral, mais simples e as recomendações mais exeqüiveis. Apesar disso, a presença na reunião de dirigentes das instituições tornou evidente que, uma vez contrariados em seus "pré-conceitos" e certezas, a assimetria nas relações de poder se fazia sentir imediatamente. Foi o caso de uma "evidência" de aumento de mortalidade perinatal associado, possivelmente, à falta de competência profissional no atendimento ao parto dos "passantes" (estudantes de medicina do último ano) no início de seus estágios num hospital da rede. A reunião correu o risco de transformar-se numa encenação, ao vivo, de piada mexicana: "como te llamas? ...(pumba!)...te llamabas". Transcrevo sem compromisso com tradução literal, os problemas abordados. Os apresentadores procediam de seis estados diferentes e, além dos executores dos projetos (pessoal de serviço elou acadêmico), estavam na reunião os respectivos dirigentes. Neste modelo de ISS o problema a investigar é trazido "por encomenda", ou é gerado no início do treinamento dos responsáveis pelo projeto. O dirigente, ou o encomendou ou, se não o fez, tem conhecimento e concordou com a prioridade atribuida ao problema analisado. Presumivelmente, no seminário a que comparecemos, aos dirigentes seriam oferecidos os sumários executivos em sua versão preliminar. Eis os problemas, identificados segundo o estado de onde procediam:

- Chiapas (Sul, fronteira com Guatemala): Participação popular no controle da Malária, em duas comunidades indígenas.

- Coyocan (periferia da Cidade do México): Participaçăo da comunidade e desnutrição, em quatro áreas.

- Michoacan (Sudeste): Cobertura da segunda dose de vacina tríplice (DPT) em trés áreas definidas segundo veiculação de mensagem educativa.

- Sonora (Norte, fronteira com EUA): Oportunidades perdidas de vacinação em crianças menores de 5 anos, em 7 Centros de Saúde Urbanos e 2 Hospitais Gerais.

- Veracruz (Sul, local da reuniåo): Oportunidades perdidas de vacinaçăo antitetánica em mulheres em idade fértil, na demanda de Serviços de Saúde.

- Zacatecas (Centro): Mortalidade perinatal num Hospital Geral, influência do treinamento dos "passantes". 
Evidentemente os problemas têm um grau de praticidade bem maior do que o encontrado nos já mencionados que figuravam no material distribuido na reunião.

Em 1992, em seminário realizado na UTMB, em Galveston, no Texas, o tema central foi a formação de uma rede de Investigação em Serviços de Saúde em paises caribenhos de língua inglesa, que não teve continuidade. Estreitamente vinculada à linha da Saúde Internacional que ultrapasse a tradição americana de considerá-la como uma espécie de vigilância dos portos, a proposta não prosperou. Ressalta-se no entanto, o que parece ser uma constante nas iniciativas recentes ligadas à OMS e à OPAS, a proposta de formação de Redes. Nesta reunião estiveram presentes, além dos americanos da UTMB, profissionais do Brasil, Uruguai, Colômbia, Guiana (inglesa) e diversos paises (ilhas) caribenhos pertencentes à "Commonwealth". Pelo menos os brasileiros negaram-se a serem considerados "representantes". Desencadeou-se confusa discussão a respeito da elaboração de uma Agenda de assuntos prioritários e do suporte técnico-cientifico a centros menos desenvolvidos, principalmente por parte de UTMB (1992).

Em 1992, em São Paulo, no Seminário do Instituto de Saúde da Secretaria de Estado da Saúde, foram apresentados projetos simples, desenvolvidos pelo pessoal de serviço e que faziam parte da experiência do Instituto na "Descentralização da Investigação para o Nivel Local"(CARDOSO, PUCCINI \& NOBUMOTO, 1990). Reservamos a análise mais detida desta experiência para um outro momento, por considerá-la uma das mais importantes no sentido do envolvimento da rede de serviços. Partindo de um edital de chamada de projetos, o Instituto de Saúde recebeu um total de 180 propostas. Um processo seletivo rigoroso, que priorizou a rede de serviços e não os grupos "acadêmicos", identificou 25 projetos, nos quais investiu US\$450,221.00, com valores variando 
entre 12 mil e 23 mil dólares. Uma temática diversificada pode ser vista na listagem dos projetos aprovados:

- Saúde Mental

- Fonoaudiologia

- Alcoolismo

$x$ Pneumopatias Ocupacionais

- Expectativa das Gestantes

$x$ Utilizaçăo dos Serviços de Saúde no Município

- Avaliação de Programa - Enfoque de Risco em Crianças

- Referencia e Contra-Referéncia

- Movimentos Sociais e Políticas de Saúde

- Comparaçăo da Estrutura de Serviços Odontológicos

- Avaliaçáo de Exames Laboratoriais

- Estudo da Intervençăo em Hospitais

x Avaliação de Serviços do Município

- Estudo da População Usuária

- Padrăo de Utilizaçáo dos Serviços de Saúde

$x$ Inserçăo do Setor Privado no Sistema de Saúde

$x$ Utilizaçåo do Pronto-Socorro

- Sistema de Custo

x Morti-mortalidade dos Acidentes de Veículos a Motor

- Análise de Óbitos Infantis (SILOS)

- Avaliaçăo de Condiçóes Sanitárias

$x$ Limites e Possibilidades da Implantaçăo de SILOS

- Inquérito de Cobertura Vacinal

- Avaliação da Imunizaçáo

- Estudo do Pronto-Atendimento de um Município

(x projetos năo executados)

Em 1992, na faculdade de Saúde Pública de USP, dentro do Programa de Hanseniase no Cone Sul, da OPAS, foi realizada uma oficina de trabalho utilizando a metodologia desenvolvida pela OMS/OPAS/IDRC de capacitação de pessoal de serviço na área de investigação. A iniciativa surgiu da evidência que o desmonte dos programas verticais teve como conseqüência inesperada perder a "inteligência epidemiológica" associada a eles. Tendo sido as atividades do programa descentralizadas, para os sistemas locais de saúde, estes niveis absorveram o controle da endemia. Novos problemas foram colocados para serem 
absorvidos e resolvidos pela periferia dos serviços, trazendo como conseqüência a necessidade de que os profissionais ai atuantes fossem capacitados. $\mathrm{Na}$ coordenação da Oficina de Trabalho atuaram professores da Faculdade de Saúde Pública da USP associados a Clovis Lombardi, responsável pelo Programa de Hanseniase da OPAS para o Cone Sul (OMS/OPS, 1992). Presentes, também, técnicos da OMS (Genebra), da OPAS (Washington e Brasília), do Ministério da Saúde (Brasilia) e da Secretaria de Saúde (São Paulo). Os participantes compuseram 12 grupos, cada um responsável pela elaboração de um projeto, assim distribuídos: Argentina (2), Brasil (6), Colômbia (1), México (1), Peru (1) e Venezuela (1). Os participantes eram oriundos dos Programas de Controle de Hanseniase, atuando em diversos niveis do Sistema de Saúde nos respectivos paises. Os projetos definiram problemas eminentemente práticos, alguns voltados para as questões da poli-quimioterapia, da alta-por-cura e da eliminação da endernia no sistema de saúde descentralizado. Identificava-se um esforço de avaliar processos de intervenção com metodologia cientifica ("pesquisaintervenção").

As diversas reuniōes mencionadas tiveram perspectivas distintas quanto à abrangência do campo da ISS. Três dentre elas, Xalapa (Veracruz, México), Galveston (Texas, EUA) e a de ISS em Hanseníase (São Paulo) filiam-se à nova perspectiva de pesquisa para ação, coordenada pela OMS e difundida, nas Américas, pela OPAS e pelo IDRC do Canadá, agência govemamental de fomento. Esta é, sem dúvida, a tendência de maior envergadura da atualidade e será analisada no próximo item. 


\section{A PROPOSTA DA OMS PARA O TREINAMENTO DE INVESTIGADORES EM ISS}

Este item sozinho merece uma análise mais pormenorizada, deixada para outra ocasião. Insere-se num contexto intemacional de movimentação das agências multilaterais, como OMS e OPAS, nacionais como IDRC do Canadá e fundações privadas, como a Rockefeller, no sentido de valorizar a investigação em saúde. Trata-se de considerar a saúde como essencial para o desenvolvimento econômico e fortalecer os mecanismos nacionais de encontrar a pesquisa apropriada para alcançar esse objetivo: a saúde e, portanto, o desenvolvimento. Existe uma Comissão Internacional com esta finalidade (BISS, 1989). Neste mesmo numero do Boletim de Investigação em Serviços de Saúde há um artigo anunciando a inclusão dos cientistas sociais entre os possiveis candidatos a treinamento em pesquisa via rede INCLEN (de Epidemiologia Clinica). É afirmado, explicitamente, que o objetivo de um novo programa da rede, induzido pela Rockefeller, é "criar nos países subdesenvolvidos a capacidade para melhorar a situação de saúde através de mudanças no comportamento". Aliás, não é demais mencionar que o periódico de divulgação BRIDGE, em inglês, BISS, em espanhol, destina-se a "facilitar o relacionamento entre os produtores e os usuários de Investigação em Serviços de Saúde e Epidemiologia Clínica". O mesmo esquema de financiamento e difusão está por trás dos dois movimentos.

Existe já vasta bibliografia relacionada com este movimento. No momento, citamos apenas uma resenha de responsabilidade do Diretor do Programa para a Investigação e o Desenvolvimento de Saúde da OMS, Yvo Nuyens, em nome de um grupo de trabalho conjunto (IDRC, OMS, OPAS) e publicado no Boletim de ISS (NUYENS, 1989). Neste artigo, menciona as iniciativas para a formação de investigadores em ISS e a publicação de uma série de manuais 
de capacitação. A mesma série é objeto de artigo, assinado por outro membro do grupo (BROWNLEE, 1991), ainda no BISS, em que se detalham os objetivos dos 5 tomos da série de Treinamento em ISS, editada sob responsabilidade do IDRC, Ottawa/Canadá, e da OMS, Genebra/Suiça.

Tomo 1. Promoçăo da ISS como instrumento gerencial.

Tomo 2. Formulaçăo e execuçăo de projetos de ISS

Tomo 3. Estratégias para Fomentar a participaçăo de universidades e institutos de pesquisa na ISS.

Tomo 4. Administraçăo da ISS, para coordenadores de projetos de pesquisa.

Tomo 5. Treinamento dos treinadores e facilitadores em ISS.

A análise detalhada de cada um dos cinco tomos é essencial para conhecer os limites e as ambições do movimento relacionado com ISS de mais fôlego (i.e., dinheiro) na atualidade. Deixamos a tarefa para outro momento, restringindo-nos a uma breve descrição de nossa experiência com a aplicação dos principios de treinamento defendidos no Tomo 2.

\section{A FLOTILHA OMS/OPAS/IDRC ANCORA NA BAIA DA GUANABARA.}

Um arrais gaúcho, Paulo Buss (FIOCRUZ), conduziu o barco ISS através da Baia da Guanabara e ancorou em Manguinhos. Fez desembarcar a tripulação: Yvo Nuyens, José Maria Paganini e Silvio Gomes, além dos mexicanos Júlio Frenk e Lilia Durán. Time completo: OMS (Genebra), OPAS (Washington), IDRC (Canadá), INSP (México). Para recebê-los, dois convidados da academia: José Noronha (UERJ) e José Carvalheiro (USP). Faziam as honras da casa (ENSP/FIOCRUZ) as professoras Marina Noronha, Ligia Giovanela e Virgínia Gawryszewski. A tripulação, recrutada durante viagem de circunavegação, vinha disposta a impor ao gentio a nova ordem: ISS à moda do reino. Aos nacionais juntaram-se posteriormente a americana Lynn Silver (ENSP) e o "espanhol" Odécio Sanches (USP, visitante na ENSP). 
Estavam criadas as condições, em solo brasileiro, para a primeira missa: um curso para treinamento do pessoal de serviço em ISS. Corria o ano de 1991 e a preparação durou meses. Tratava-se de realizar uma experiência de aplicação do Tomo 2: Formulação e execução de projetos de ISS, da já mencionada série de Treinamento em ISS, publicada pelo IDRC e a OMS. Uma edição em espanhol, reponsabilidade mexicana, serviu de base para versão preliminar em português, realizada pelo escritório da OPAS/OMS em Washington. A primeira missão do grupo nacional foi uma rigorosa revisão do exemplar traduzido para o português. Tive oportunidade, na ocasião, de elaborar uma análise critica do material, que passo a transcrever pois mantenho, na essência, a mesma opinião a respeito.

\section{CONSIDERAÇÕES A RESPEITO DO "CURSO DE ENTRENAMIENTO EN INVESTIGACIÓN EN SISTEMAS DE SALUD-VOLUMEN II"(*)}

O material destina-se a ensinar "como desenvolver propostas de investigação para resolver problemas prioritários de saúde". É dividido em 20 módulos que agrupamos, para efeito de análise, em 3 blocos:

BLOCO 1: - Módulos 1 a 5 : Orientaçăo de curso, conceito de ISS, seleçăo de temas e formulaçăo de objetivos.

BLOCO 2: - Modulos 6 a 13 : Metodologia da ISS.

BLOCO 3: - Módulos 14 a 20 : Administraçăo, Orçamento, Relatórios.

A análise do BLOCO 1 permite, ultrapassando seus limites, tecer considerações a respeito da proposta pedagógica e seu desdobramento. Como sempre acontece quando se utiliza técnica de INSTRUÇÃO PROGRAMADA, a proposta mostra-se linearizante e fragmentária, com os seguintes aspectos (que não são exclusivos desta proposta):

(*) Com a colaboração de Ausônia Favorido Donato e Luiza Sterman Heimann. Instituto de saúde SES/SP apresentado à ENSP. Rio de Janeiro. abril de 1991. 
- tem como alvo comportamentos finais

- apresenta definiçסes e não conceitos

- náo provoca ambigüidades

- as definiçóes săo primárias

- tem grande coerencia interna, essencial à técnica usada

- é adequada para o ensino de técnicas

Esta última característica da instrução programada indica ser ela mais adequada à formação de técnicos (em ISS, neste caso). Nem deve ser outro o sentindo da palavra "Investigantes", empregada no texto "Ante-proyecto para la realización de un curso de capacitación en ISS en los SILOS en Brasil" (ENSP 1990).

Cabe, portanto, uma reflexão a respeito do que se pode esperar da utilização desta proposta no contexto brasileiro. É bom assinalar que o mesmo "Ante-proyecto", indica que foi decidido reproduzir no Brasil, o Curso de Capacitação em ISS, módulo II, tal como foi concebido ("diseñado") e desenvolvido no INSP/México. A experiência mexicana ainda está em curso e é possivel que a análise de seus resultados aponte para uma adequação ao contexto, sem necessariamente implicar numa extensão imediata aos demais paises da América Latina. Em nosso contexto, há esforços de introdução de ISS nos Cursos de Saúde Pública, mestrados e doutorados de Saúde Pública, Medicina Social e outras áreas da Saúde Coletiva. Em todos esses casos trabalha-se com profissionais graduados em carreiras bem definidas: médicos, enfermeiros, sociólogos, farmacêuticos, etc. Os que são atraidos para ISS geralmente já foram expostos, em seus cursos de graduação e de pós-graduação ou especialização, à metodologia epidemiológica de inquéritos ("surveys"), que é o eixo condutor desta proposta. Há que pensar maduramente nesta questão ao se estabelecerem as regras de recrutamento dos participantes do Curso proposto, sem o que os riscos de insucesso serão grandes. 
A proposta está inserida num movimento com características de rede, a julgar por sucessivas matérias de diversos números do "Boletin de ISS", editado por Programas da OMS, OPS e pela Rede Internacional de Epidemiologia Clínica e Fundação para a ISS, com apoio da Fundação Rockefeller e do Centro Internacional de Investigações para o Desenvolvimento (IDRC, Canadá). Não há mais cabimento para "patrulhamentos epistemológicos", porém, não é demais assinalar que a construção do objeto da Saúde Coletiva, a Epidemiologia Social em particular, é processo com larga tradição no Brasil e em diversos outros países da América Latina, inclusive o México.

Nesse sentido seria inconcebivel aproveitar os Módulos iniciais (Bloco 1) sem crítica. A propósito, as idéias introduzidas por Marc Lalonde na década de 70 , no Canadá, pareceriam até mais adequadas. Especialmente o conceito de Campo de Saúde (Lalonde, 1974), com maior força e singeleza do que os absolutamente anti-didáticos diagramas de interação, presentes nos primeiros módulos do Curso.

Apresentá-los para simplesmente criticá-los, também não tem sentido: torpedearia a coerência interna, essencial à técnica de instrução programada. Suprimi-los, é uma alternativa. Substituí-los, a outra. Há que decidir a respeito, sempre tendo em mente que não se trata de formar investigadores para interrogantes de elevado grau de abstração: está mais para a pesquisa operacional, tão importante para a solução de problemas simples e concretos. Não precisamos justificar nossa adesão a esta ou aquela concepção de mundo (c.d.m.), se o problema em estudo estiver restrito ao funcionamento interno de um serviço de saúde. Então não há, obrigatoriamente, que apresentar nenhuma c.d.m.. O exemplo mais simples vem do campo das matemáticas: a instrução programada é fantástica para o ensino-aprendizagem de técnicas. Não se exige, portanto, nenhuma adesão a qualquer das correntes filosóficas que discutem a natureza da matemática para aprender a extrair uma raiz quadrada. 
Na mesma linha de pensamento, o Módulo 4, que trata da Revisão Bibliográfica, deveria ter sua orientação modificada. Se a revisão bibliográfica não é conduzida e interpretada por um investigador profissional, é uma contrafacção. Nem por haver, atualmente, mais facilidades para obtenção de listas bibliográficas, por mecanismos automáticos e transmissão à distância, a análise dessas listas prescinde da inteligência e do talento de um profissional em dia com o "estado da arte". Não se pode imaginar um desenvolvimento autônomo (absoluto) da ISS a nivel dos serviços, prescindindo dos profissionais "do ramo". A menos que se pretenda formar investigadores de $2^{a}$ categoria, para produzir resultados identicamente de $2^{a}$ categoria. Nem se diga que falta suporte, no Brasil, a ISS desenvolvidas na rede, com apoio de Escolas de Saúde Pública, Departamentos de Medicina Preventiva e/ou Social e Núcleos de Investigação espalhados pelo país. A própria proposta tem esta concepção: durante o treinamento, os participantes ficam em estreito e permanente contato com os coordenadores e, especialmente, com os facilitadores. Eliminada a idéia de multiplicação autônoma, este papel terá que ser ocupado após esta fase inicial de capacitação.

Uma proposta pedagógica alternativa para todo o Bloco 1 implicaria:

- sessão preliminar, com a caracterização do grupo (origem, afinidades, etc.) e levantamento de sua percepção quanto ao universo da investigação (préconceitos).

- apresentação do Bloco 1 de módulos, revistos, permitindo contextualizar o processo de ISS e a atuação dos diversos agentes. Discutir a "profissionalização" da pesquisa.

- selecionar temas de investigação, identificando processos, formulando hipóteses, definindo objetivos.

A crítica ao Bloco 1 de módulos não deve ser encarada como falta de compreensão a respeito da necessidade de difundir, quanto mais, melhor, a ISS. 
Somente quadros efetivamente engajados terão suficiente motivação apara empreender ISS no seu âmbito de ação. Para resolver problemas concretos. 0 que não é possível é encarar este esforço com ilusão de autonomia completa em relação ao trabalho acadêmico. A produção do conhecimento é, essencialmente, um trabalho que exige assiduidade, dedicação e atualização continua. Não se pode pensar a reprodução da máquina de produzir conhecimento novo, com a simplicidade da transmissão de técnicas consolidadas. É o que se fez, com algum sucesso, usando os módulos dos "Princípios de Epidemiologia para el control de enfermidades", editados pela OPS (1979). Mas aqui é diferente. Ou se dá aos módulos iniciais uma abrangência modesta, confessando explicitamente uma visão limitada à pesquisa operacional e suas técnicas ou se modificam radicalmente os mesmos, concluindo-os com uma discussão aberta com o grupo recrutado, a respeito da profissão do cientista. Não é demais recordar a distinção que Álvaro VIEIRA PINTO (1979) faz ("Ciência e Existência") entre a transmissão do conhecimento acumulado ("conhecer para ficar sabendo") e a produção do novo ("conhecer para não ficar sabendo"). Ensinar a técnica de inquéritos ("surveys") para ser aplicada como instrumento do trabalho cotidiano de alguns setores da rede pode ter pouco a ver com a ilusão de estar inundando a mesma rede de investigadores em serviços de saúde. Talvez esteja ai o sentido do termo investigante.

O BLOCO 2 concentra a apresentação das técnicas envolvidas nos inquéritos epidemiológicos ("surveys"). Está formalmente bem apresentado, sendo possivel identificar, em sua ordenação e profundidade, influência de textos conhecidos (Ex.: Survey Methods in Community Medicine, J. H. Abramson). Poderiam ser propostas mudanças, o que implicaria quase criar um novo instrumento. $O$ que, parece, está fora de cogitação. Seria, inclusive, perdido o sentido da comparação internacional do emprego de uma técnica de instrução 
programada para ensinar procedimentos técnicos de investigação. Nada impede que se introduzam textos adicionais. Apenas à guisa de exemplos:*

SIEGEL, S. (1956) Nonparametric statistics for the behavioral sciences. Mc Graw Hill. Capítulo de Mensuração, em que são introduzidos os níveis das diversas escalas (nominal, ordinal, intervalo e razão) e discutidas suas relações com as variáveis e testes estatisticos.

ABRAMSON, J.H. (1979) Survey methods in Community Medicine - An introduction to epidemiological and evaluative studies. Churchill Livingstone, London. Alguns tópicos específicos que acrescentariam uma visão alternativa aos temas tratados.

RUMEAU-ROUQUETTE, C.; BREART, G. \& PADIEU, R. (1985) Méthodes en Épidémiologie - Échantillonage, investigations, analyse. Flammarion, Paris. Especialmente o capítulo de Estratégia da Epidemiologia, em que são discutidos os 3 grandes eixos: informação sobre 0 estado de saúde da população, pesquisa etiológica e avaliação de intervenções visando a melhorar o estado de saúde da população.

PEAVY, J.V. \& DYAL, W.W. (1980) Community disease and immunization survey. U.S. Depto. Health, CDC. Desenvolvido para ser usado com pouca ou nenhuma consultoria externa.

MOSER, C. A. (1958) Survey methods in social investigation. Heinemann, London. Especialmente os capitulos de amostragem.

\footnotetext{
* Nota: a crítica era endereçada ao nível internacional, o que explica a ausência de obras nacionais entre os exemplos.
} 
O BLOCO 3 concentra os módulos mais propriamente relacionados com a administração do projeto de investigação, a redação da proposta final, com cronogramas físicos e financeiros, os relatórios parciais e o final. Obriga a analisar as normas existentes em diversas agências. Em nosso caso será útil introduzir na discussão os procedimentos preconizados por FINEP, CNPq, FAPERJ, FAPESP, PESPS/MS, e outros.

Em conclusão, não podemos eliminar a idéia de participar dum processo que ganha corpo a nivel internacional, vinculado a agências como OMS, OPS e outras. Devemos evitar a atitude paralisante de apenas desenvolver estudos com suficiente alcance teórico, capaz de apreender a complexa trama de determinações do processo saúde-doença e do desempenho dos serviços de saúde. Há lugar para estudos mais simples, destinados a entender e propor medidas de menor complexidade. Para desenvolver estes estudos há necessidade de pessoal adestrado.

O que não se pode conceber é que se restrinja a ISS aos inquéritos ("surveys"). Este ponto deve ser enfatizado no bloco 1, ainda que o curso continue a priorizar as técnicas de inquérito.

O que é ainda menos concebivel é a adesão pura e simples a uma proposta que nada tem de neutra: está ideologicamente vinculada a uma corrente perfeitamente identificada. Gato escondido, com o rabo de fora: esta tendência está claramente delineada no Bloco 1 de Módulos. Sem a supressão, ou ampla modificação, deste Bloco 1, torna-se difícil imaginar a Saúde Coletiva brasileira metida nesta empreitada. 


\section{DE MANGUINHOS À CHÁCARA DAS ROSAS}

O treinamento chamou-se "Curso de Investigação em Serviços de Saúde" e foi oferecido sob a responsabilidade da ENSP/FIOCRUZ. Farei dele um relato extremamente sucinto por se tratar de realização coletiva que merecerá análise mais ampla e detalhada, com os devidos créditos a todos os participantes.

Seguiu as recomendações dos manuais produzidos pela OMS e IDRC. Inicialmente, uma reunião com dirigentes de nove instituições públicas interessadas em participar. Chamada Reunião de Sensibilização, pouco deve ter adiantado: as instituições foram escolhidas através de contatos pessoais com dirigentes já previamente "sensibilizados". Alguns problemas foram então enunciados e indicados os profissionais que seriam treinados. No correr do curso, alguns temas foram modificados mas não houve grandes alterações. Cada instituição indicou entre 1 e 5 servidores porém, por razões diversas, o curso terminou por ser oferecido a 17 participantes regulares.

Houve um treinamento prévio, na ENSP, de familiarização com a Biblioteca e suas fontes de informação: livros, anuários, revistas, etc. A primeira etapa do curso, com duas semanas de duração, realizou-se num pequeno hotel de Petrópolis, a "Chácara das Rosas", vizinho de uma instituição de ensino voltada para computação e informática. Houve treinamento para uso do computador, aulas, seminários, exercícios e muito trabalho prático para a elaboração de 9 projetos:

1. Estudo do perfil da clientela do ambulatório do PAM-RAMOS, R.J. (1 médico, 1 assistente social).

2. Estudo do cumprimento do tratamento medicamentoso de hipertensăo arterial rio CSE da ENSP/FIOCRUZ, R.J. (1 enfermeira, 1 assistente social).

3. Estudo da qualidade da atenção em Puericultura do Ambulatório do Hospital Raphael de Paula Souza ("Curicica"), antes e após intervençăo com énfase no envolvimento profissional, R.J. (1 médica, 2 assistentes sociais). 
4. Fatores relacionados ao abandono de tratamento de Tuberculose Pulmonar e medidas de intervenção: estudo de caso do CMS da XI RA, R.J. (1 médica).

5. O agente de saúde de Săo José dos Campos: sua evoluçăo desde a implantaçăo do programa em 1979 até o ano de 1990, S.P. (2 médicas).

6. Estudo exploratório e retrospectivo sobre as condiçסes de admissăo dos casos de Doença Meningocócica no Instituto Estadual de Infectologia Săo Sebastiăo e suas conseqüéncias para o paciente, R.J. (1 enfermeiro, 1 assistente social, 1 auxiliar de enfermagem).

7. Estudo dos fatores associados à interrupçăo do seguimento no tratamento $e$ acompanhamento dos pacientes de Cáncer no Instituto Nacional do Câncer, durante um ano após terem sido registrados, $R$.J. (1 enfermeira, 1 assistente social).

8. Avaliaçăo da mortalidade geral do Hospital Municipal Dr. Mário Gatti, no $2^{\circ}$ semestre de 1988 e $2^{\circ}$ semestre de 1990, Campinas, S.P. (1 farmaceutica-bioquímica).

9. Perfil do atendimento de enfermagem ao paciente na Unidade de Intervençåo do Hospital de Ipanema - SES/SUS, R.J. (1 enfermeira).

Após as duas semanas de treinamento, com seus projetos elaborados até o nivel de detalhamento de cronogramas de execução física e financeira, os participantes retomarem a seus locais de trabalho para executá-los. O custo total dos nove projetos atingiu US\$ $60,505.00$, sendo US\$ $24,083.00(39,8 \%)$ financiado pela OPAS/OMS e US\$ $36,422.00(60,2 \%)$ de contrapartida das diversas instituições. Cada projeto custou, em média, US\$ 6,722.80, o que não difere substancialmente dos valores internacionais nesta proposta de ISS.

Após seis meses, obtidos os resultados, foram eles analisados pelos executores dos projetos com auxílio dos coordenadores do Curso, em outra sessão de duas semanas na Chácara das Rosas, em Petrópolis. Dirigentes dos diversos órgãos envolvidos foram convidados e compareceram para ouvir a apresentação do sumário executivo. Vários problemas ocorreram durante a execução dos projetos e mesmo após a apresentação final dos sumários. Nada parecido com o mencionado episódio ocorrido na apresentação de Xalapa quando um dirigente exibiu inconformismo contundente. Porém, ficou claro que também em nossa experiência o processo gera tensões, às vezes dificeis de contomar. Este ponto certamente será focalizado quando o coletivo envolvido no processo publicar seus 
resultados. Antecipo, no entanto, que nem tudo foram rosas na reunião final na chácara homônima.

\section{A EFICÁCIA DA REDE É O TAMANHO DA MALHA}

A apresentação da seqüência do trabalho também será extremamente sintética. Já era idéia inicial atribuir à experiência brasileira um papel indutor do estabelecimento de uma Rede de ISS no Cone Sul da América Latina. Sob a coordenação de Paulo Buss, foram realizadas negociações na tentativa de construção dessa rede. Acrescentaram-se novos participantes e a ENSP, associada ao Instituto de Saúde de São Paulo, patrocinou um seminário sobre "Investigação em Sistemas e Serviços de Saúde no Cone Sul: estratégias para a construção de uma Rede de Cooperação", realizado, em abril de 1994, no Rio de Janeiro. Como tarefa preliminar, com financiamento da OPAS e do IDRC, emissários das duas instituiçōes estabeleceram contatos diretos com centros de investigação na Argentina, Brasil, Paraguai e Uruguai não apenas para formular convites para sua participação no Seminário, também para estabelecer as idéias básicas que deveriam, por consenso, orientar a organização da Rede.

Nesta etapa apareceram divergências. Grupos já consolidados, numa perspectiva mais abrangente do que é investigar em saúde, expressaram seu desconcerto com uma proposta que consideravam banalizadora da ISS. A principal demonstração de desagrado surgiu do consagrado pesquisador argentino Mário Testa que fez chegar aos interessados sua opinião (TESTA, 1994). Em que pese todas as adversidades, realizou-se o Seminário.

Iniciou-se com exposições genéricas a respeito de ISS e foram discutidos os resultados da experiência brasileira. Concluiu com uma "Carta do Rio de Janeiro" (ENSP, 1994), além de um Relatório Final (NORONHA \& 
GAWRYSZEWSKY, 1994), ambos apontando para a necessária composição da Rede Cone Sul.

$\mathrm{Na}$ seqüência realizaram-se mais algumas reuniões $e$, finalmente, divulgou-se uma "Convocatória de Investigação em Serviços de Saúde para Argentina, Brasil, Paraguai e Uruguai", da Rede, já formalizada, com apoio do IDRC e da FIOCRUZ (REDE, 1995). Esta nova experiência, ainda está em curso e será certamente analisada no futuro. Comento apenas que a Rede recebeu 58 propostas, assim distribuídas: Argentina (16), Brasil (30), Paraguai (1), Uruguai (11) (LOBO, 1995).

Desejo aproveitar o ensejo para expressar algumas idéias a respeito da composição de redes desta natureza. Não considero missão das mais simples, por envolver simultaneamente elementos de natureza epistemológica, política e, mesmo, ética. Seja esta contribuição entendida como indutora do debate, que se torna urgente e absolutamente necessário se quisermos avançar, no Cone Sul, em direção ao futuro mas sem abandonar compromissos arduamente construídos no passado.

Acredito que ao menos três elementos devem ser trazidos a esta discussão. De um lado, a questão das redes encarada em seu desenvolvimento recente e não como mera articulação burocrática e administrativa. Refiro-me à Teoria das Redes, "que vem sendo desenvolvida para análise dos fatos científicos" (CONCURD/ENSP, 1991). Aproveitando as idéias de LAW (1989) e, especialmente de CALLON (1989), os autores desse documento da ENSP desenvolvem argumentos para a constituição de uma "Rede de Formação em Saúde Coletiva no Brasil" perfeitamente superponivel ao problema que estamos analisando relacionado com o apoio acadêmico à constituição de uma Rede de ISS, no Brasil e no Cone Sul. A complexidade das redes, ou melhor do Sistema de Redes e de seus 
porta-vozes é um esquema perfeitamente adaptável à construção que temos em mente. Cada rede elementar é representada no sistema complexo por porta vozes ou representantes que, "ao serem mobilizados, mobilizam com eles todos os atores humanos ou não humanos que eles representam" (CALLON, 1989). O papel de porta voz pode ser representado por um equipamento, que tanto pode ser uma ressonância nuclear magnética como em mero termômetro clínico. Pode ser uma publicação técnica ou cientifica e, claro, um cientista. Seria irônico, se não fosse trágico, excluir do elenco de porta vozes os trabalhadores da rede de serviços de saúde.

O segundo elemento a incluir na discussão resulta do desenvolvimento das idéias recentes no campo da epistemologia e da metodologia, trazidas à baila por autores como SAMAJA (1995). Suas idéias a respeito do conjunto de matrizes de dados, "invariante estrutural dos dados cientificos de qualquer ciência empirica", converge para auxiliar na compreensão do que representa a produção do conhecimento numa rede complexa. A matriz central depende do que o autor chama nivel de ancoragem da investigação, escolhido entre todos os niveis possiveis. Além desta, existem pelo menos outras duas matrizes: "uma subunitária, constituida pelos componentes das unidades de análise do nivel de ancoragem; outra supraunitária, constituida pelos contextos das unidades da matriz central" (SAMAJA 1995). A inclusão da ISS realizada, nos serviços, pelo pessoal dos serviços, é um componente óbvio e tanto pode contribuir para a matriz central, como para matrizes subunitárias. Aprimorar a capacidade do pessoal de serviços na produção destas matrizes é a tarefa impar que devemos assumir se quisermos uma Rede de ISS eficaz.

O terceiro elemento nos é trazido por algumas das reflexões mais argutas de Mário Testa, importante intelectual da Saúde Coletiva na América Latina (TESTA, 1992). O seu postulado de coerência afirma que "os propósitos de uma 
instituição, os métodos que utiliza e a organização que assume devem ser coerentes". Embora um investigador externo possa dar conta desses meandros complexos, ninguém melhor do que trabalhadores dos serviços para refletir sobre eles. No entanto, cautela: o mesmo autor (TESTA, 1992) alerta sempre para a necessária inclusão do poder (técnico, administrativo ou político) como elemento essencial na análise. Considera a "estratégia como forma de implementação de uma política e esta como uma proposta sobre a distribuição do poder". Não será, portanto indiferente que a análise seja feita por quem participa, ou está alheio, à luta pela partilha do poder.

Em síntese, a definição que viermos a dar a nossa tarefa de construção de redes de ISS conduzirá fatalmente ao significado social das mesmas. A isto estamos chamando relação da eficácia da rede com o tamanho da malha. Se articularmos, apenas, dirigentes de alta hierarquia dos serviços com setores acadêmicos de escassa atuação na prática, estaremos estendendo redes para captura de tubarões e outros peixes graúdos, deixando escapar os lambaris. Partindo para o extremo oposto, exclusivamente pessoal de pequena capacitação técnica da periferia do sistema de saúde, corremos o risco da absoluta improdutividade, da extinção da fauna ictiológica.

No caso particular do Estado de São Paulo já analisamos a questão, embora de maneira preliminar, em trabalho anterior (CARVALHEIRO, 1993). Propúnhamos para o Instituto de Saúde, da Secretaria Estadual, um papel de articulação dos núcleos de investigação do Estado na composição de um Polo Tecnológico com estrutura informal, capaz de dar sustentação ao processo de implantação do SUS. Uma espécie de redes em série, capazes de capturar, seqüencialmente, desde tubarões até lambaris. 


\section{ISS/ABRASCO: SIMPATIA É QUASE AMOR*}

Algum tipo de ISS sempre existiu. Acho até que, sem grande esforço, podemos classificar "Ares, Águas e Lugares" numa das categorias de ISS e seu autor como ilustre pioneiro da proposta de fazer pesquisa científica com pessoal de serviço, contribuindo para importante transformação epistemológica ao desviar a responsabilidade pela saúde: dos deuses para os indivíduos e os médicos que os aconselham. ${ }^{* *}$

O debate epistêmico não é exclusivo deste campo da saúde. Na verdade, de nenhum campo do conhecimento. A questão é saber que importância dar à produção do conhecimento originada nos próprios serviços. Nessa mesma linha de pensamento, como elidir as tendências de colonialismo intelectual, não apenas no âmbito internacional. $O$ aproveitamento dos dados gerados em qualquer serviço não é proposta recente. Sua transformação em informações válidas para ter ingresso no debate científico também é antiga prática da investigação clínica e epidemiológica. Talvez seja crítica a discussão a respeito do agente desta transformação: quem é o cientista? É um acadêmico, um investigador de plenos direitos ou pode ser, conforme assinalam documentos deste movimento recente de rede internacional ISS, um "investigante"? A questão é, ela sim, instigante.

\footnotetext{
"O título deste ítem é modesta homenagem ao Bloco Carnavalesco "Simpatia é quase amor" de Ipanema, no Rio, onde nos domingos de carnaval podem ser encontradas expressivas lideranças do Movimento Sanitário Brasileiro.

** A obra completa atribuída a Hipócrates, Coleção Hipocrática (ou Corpus Hippocraticum), composta de aproximadamente 60 títulos, é resultado do trabalho de diversos autores. Estende-se do quarto ao décimo século A.C. o que por si só é evidência suficiente de mais este legado de Hipócrates à medicina: atribuir ao catedrático as obras dos discípulos. Além do já mencionado Ares, Águas e Lugares, pertence também à coleção um tratado sobre Epidemias, de sete volumes, escrito pelo menos por dois autores (UNDERWOOD, 1992; VON STADEN, 1995).
} 
Analisando esta questão com maior atenção, verifico estarmos vivendo, no Brasil, o que talvez seja a mais expressiva experiência de ISS com pessoal de serviço de todo 0 mundo. $O$ que aumenta substancialmente nossa responsabilidade. Participo deste esforço desde sua origem, desde a fundação da Associação Brasileira de Pós-Graduação em Saúde Coletiva (Abrasco). Foi em outubro de 1977 que um grupo de aproximadamente 20 pessoas deixou o Anhembi, onde se realizavam o XIX Congresso Brasileiro de Higiene e o $1^{\circ}$ Congresso Paulista de Saúde Pública, atravessou discretamente a avenida e reuniu-se, quase clandestinamente, na cantina dos oficiais do Campo de Marte, aeroporto pequeno e quase desconhecido situado no centro de São Paulo. Ali surgiu, de fato, a Abrasco, com a "pós-graduação" no nome, mas não na sigla. O momento era difícil, a ditadura brasileira não dava tréguas. É irônico que o lugar de criação de uma entidade que iria afrontar a ditadura militar tenha sido uma "cantina de oficiais". Era o momento da consolidação do Movimento de Reforma Sanitária Brasileira. A reunião mencionada pode ter sido a primeira do que, no processo, veio a ser chamado Partido Sanitário (PS), de indiscutivel presença na inserção do capítulo sobre saúde na Constituição de 1988.

Apenas menciono esses fatos para, num salto de quase 20 anos, contemplar o que é hoje a Abrasco. Uma associação científica e, ao mesmo tempo, um movimento. Deixemos de lado seu papel na construção da Reforma Sanitária Brasileira, no campo político e ideológico. Pensemos em seus Congressos, especialmente os últimos de Saúde Coletiva ("abrascão") e de Epidemiologia. São milhares de participantes, em todos eles, rivalizando com as Reuniões Anuais da SBPC. No caso dos Congressos da Abrasco, não são participantes passivos, leigos em busca de uma divulgação da ciência. As reuniões da SBPC cresceram após 1964 porque eram um dos poucos momentos anuais em que se ousava contestar a ditadura. Dai em diante, nunca mais tiveram sua expressão numérica (e política) diminuída. Os Congressos da Abrasco representaram o mesmo papel na área de 
saúde. Não apenas a intelectualidade, a saúde inteira está nos congressos. Notadamente o pessoal dos serviços, que tem o "atrevimento" de apresentar trabalhos. Claro que lideranças dos serviços sempre tiveram lugar: como debatedores, palestrantes ou, até mesmo, conferencistas. Não é a isto que me refiro, é aos milhares de apresentadores de modestos "posters" nas sessões de temas livres (Abrasco, 1992; 1992-A; 1994; 1995). Não é este o local adequado para uma discussão quantitativa, nem mesmo da diversidade temática das contribuições. Posso assegurar que é fenômeno da maior importância, digno de merecer atenção de investigadores profissionais, que se debrucem nesta quase meta-ISS. Neste artigo menciono algumas (poucas) dezenas de ISS: nos congressos Abrasco devem estar na casa dos milhares!

Por fim, mas não menos importante, lembremos a Associação Paulista de Saúde Pública (APSP) e seus congressos. Além, é claro, de sua revista: por coincidência, esta Saúde e Sociedade. Deixemos para terceiros a análise, não queremos ser vítimas da tentação do vitupério.

\section{ISS E O MAIOR DOS SEUS PROBLEMAS}

Até aqui nos limitamos a analisar um conjunto de problemas externos à ISS entendida enquanto atividade científica propriamente dita. Percebe-se que não são poucos, mas talvez não sejam os principais. Acredito que o principal problema é o da delimitação do objeto da ISS. Daí decorre a construção metodológica que, na visão de BRUYNE et al (1982), deve ser encarada como processo dialético de interação simultânea de quatro pólos: epistemológico, teórico, morfológico e técnico. Se optamos por uma ISS que se confunde com o todo da investigação em saúde, pouco teremos a acrescentar ao que certamente está contido nos demais artigos deste número de Saúde e Sociedade. Especial atenção deve, então, ser 
dada ao polo epistemológico, que "renova continuamente a ruptura dos objetos científicos com os do senso comum".

A verdade é que reina confusão nas tendências majoritárias de ISS, que tendem a entendê-la como uma mistura, em proporções variáveis, de pesquisa operacional e pesquisa aplicada, tal como define BAILEY (1977). Isto já seria suficientemente embaraçoso se nos limitássemos à pesquisa sobre serviços de saúde, realizada por investigadores profissionais. Ao introduzir a idéia da realização da ISS pelo pessoal dos serviços o que se faz, geralmente, é confundir o processo metodológico com seu polo técnico que "controla a coleta de dados", esquecendo que ele "esforça-se por constatar dados que podem ser confrontados com a teoria que os suscitou". Neste adendo, que traz implicito o polo teórico e mesmo o morfológico, encontra-se o ponto crítico capaz de diferenciar um investigador de um "investigante". O que contribui para conturbar ainda mais o ambiente é que as propostas de coleta de dados, formuladas pelo investigador, não diferem nada dos dados de que se aproveitam os trabalhadores dos serviços em suas tarefas quotidianas, que incluem tomar decisöes a cada momento.

Espantoso é que a gritaria seja bem menor em outros campos em que se faz exatamente o mesmo. Refiro-me, para manter-me no campo da saúde, às investigações baseadas em prontuários médicos: sejam clínicas ou de epidemiologia clínica. Para não falar da vigilância epidemiológica, da vigilância de efeitos adversos de medicamentos, do estudo da natureza das lesões associadas a causas externas de acidentes e violências. Grande parte do conhecimento relacionado com a história natural das doenças, em particular estudos de prognósticos e valores preditivos diagriósticos, deriva dessa origem comum: o prontuário médico. $O$ registro das ações de rotina é idêntico ao que se propõe fazer o polo técnico da pesquisa: a coleta de dados. Afirmar que a diferença reside numa tentativa (no caso da pesquisa) de confrontar os dados obtidos com a teoria (e a 
hipótese) que os suscitou é ousadia excessiva. Traz implícito que, no cotidiano, apenas se realizam ações automáticas e de maneira acritica. A tênue linha que separa as duas práticas (coleta de dados de pesquisa e registro de ocorrências da prática diária) é mais vezes violada do que o cessar fogo na Bósnia. A propósito, não há uma guerra entre essas práticas. Pelo menos ninguém o contesta no caso da pesquisa no indivíduo. Buscam-se processos de manipulação dos dados capazes de dar conta da variabilidade devida à multiplicidade de observadores não exaustivamente treinados e padronizados.

Em algumas ocasiōes tem-se visto aparecer contribuições notáveis, produzidas pelos profissionais nos serviços de assistência. Líder dos médicos ingleses, no árduo processo de construção do Sistema Nacional de Saúde, John Fry, médico generalista (G.P.) atuando em Beckenham, Kent, nas proximidades de Londres, ainda teve tempo para escrever um livro sobre Perfis de Doenças Comuns (FRY, 1966). Com abordagem de extrema originalidade, encarando a doença com olhar de um trabalhador da linha de frente. Modesto, o autor indaga no Prefácio: "por que deveria uma abelha operária ('working bee'), um médico de família, um G.P., ser presunçoso a ponto de escrever um livro sobre os perfis das doenças?" Ele mesmo adianta uma resposta plausivel, que nos espanta pela atualidade, passados 30 anos: "deve-se entender que um médico geral atuante pode contribuir para o conhecimento médico num mundo que está se tomando cada vez mais cego pela ofuscante invasão da Ciência e Tecnologia na medicina atual". E arremata com uma frase de efeito que encerra a essência do que pode representar em importância a produção de conhecimento nos serviços: "os achados da prática ... podem contribuir um pouco para o nosso conhecimento da história natural da doença no homem e da história natural do homem na doença" (!) Os grifos e a exclamação são nossos e não hesitamos em parafraseá-lo: os achados da ISS feita nos serviços pelo seu pessoal podem contribuir muito para 0 
conhecimento da política de saúde nos serviços e, especialmente, dos serviços na política de saúde.

Por que, então, a celeuma quando se trata de ISS? Só pode ser pela maior visibilidade da determinação social, politica e econômica dos processos estudados. No individuo, ao analisar fenômenos presumivelmente do âmbito biológico, admite-se que as técnicas de coleta de dados têm maior objetividade. Mesmo sem ser aferidos, confia-se cegamente nas medidas de pulso, pressão e temperatura, ordenados na prescrição do médico pela sigla PPT e colhidos geralmente por auxiliares de enfermagem, ou mesmo por atendentes. Já quando se analisam os processos no âmbito do social, a ninguém ocorreria fazê-lo sem estar referido a um marco teórico. O nosso problema paira entre esses extremos num ponto impreciso. Quando se aproxima de um dos extremos, geralmente não há dúvidas. A confusa região intermediária é a questão, ai precisamente localiza-se a ISS.

Apenas para nos reportarmos aos problemas com que tivemos contato direto, comparemos dois deles. O projeto sobre a qualidade de atenção em Puericultura num ambulatório (Curicica), usando uma medida de intervenção e adotando como indicador a melhoria da qualidade de preenchimento do prontuário, delimita um objeto-problema de natureza aparentemente menos complexa. 0 estudo sobre as condições de admissão dos casos de doença meningocócica no Hospital São Sebastião configura um objeto aparentemente mais complexo, pela determinação social do surgimento da doença e também pela da diversidade do fluxo dos doentes até o Hospital. Pode ser que essa diferença entre os projetos seja apenas aparente e que, encarados de uma outra perspectiva de análise, apresentem igual complexidade na rigorosa determinação do objeto. 
Se não pudermos satisfazer a todos os desejos simultaneamente, e não podemos, renunciemos a isto. No caso da ISS, trata-se de uma questão de ensaio e erro. Por exemplo, espera-se que apenas "sobrevivam" as experiências vitoriosas de municipalização da saúde, uma verdadeira seleção natural pressionada pela política de financiamento e pelo controle social. O mesmo deve ocorrer com a ISS e sua aplicação na rede de serviços. Propostas de ISS deslocadas (ou descoladas) da realidade e com articulação metodológica (especialmente epistemo) irreal serão sumariamente descartadas. É evidente que, ao opinar sobre o seu trabalho cotidiano, um trabalhador passa por menos confiável do que quando se limita ao mero registro de variáveis consideradas objetivas (por ex. PPT). Parece que se considera perigoso, para os desígnios da ciência, dar voz aos trabalhadores ou à população. Algumas das novas propostas de pesquisa na sociedade, como as das representações sociais, superam esta contradição. Jodelet, citada por CREPALDI (1995), considera que "as representações sociais são modalidades de pensamento prático, orientadas em direção à comunicação, à compreensão e ao domínio do ambiente social, material e ideal". É claro que ao enveredarmos, na ISS, por novos modelos de investigação, somos obrigados a recorrer a disciplinas afins e a incorporar a metodologia adequada, que acompanha a disciplina migratória, inclusive no seu polo técnico. Refiro-me a técnicas qualitativas de coleta de dados, como a observação participante, com seus diários de campo, a pesquisa-ação, e as entrevistas, entre outras.

Não me preocupa a capacidade de interpretação dos atores. Considero essencial assumir, como já foi dito, que em qualquer circunstância suas manifestações (verbais, escritas, comportamentais) são porta vozes de uma rede singular (CALLON, 1989) e contribuem na composição do conjunto de matrizes de dados (SAMAJA, 1995), no nivel de ancoragem ou abaixo dele. Devemos abandonar a idéia simplista de que fora dos métodos quantitativos não há salvação. Este vezo quantitativo talvez explique a ênfase que se dá aos inquéritos 
("Surveys") na ISS preconizada pelos Manuais da OMS/OPAS/IDRC. Quanto a quem vai interpretar os dados, também não me preocupa. Cada um o fará com seu próprio instrumental e seus próprios vieses. As fontes primárias são, em si, viesadas. Penso na realidade brasileira expressa nas gravuras de Debret ou Rugendas e nos trabalhos em barro do mestre Vitalino. Mas penso, também, no observador secundário que busca inteirar-se dessa mesma realidade através da obra dos artistas. Um europeu olhando os bonecos de barro e um sertanejo espiando as gravuras, ou inversamente.

Noutro dia encontrei um painel eletrônico com propaganda de vôos de helicóptero para fugir do engarrafamento do trânsito. Para simular a hélice em rotação usaram, na parte superior do desenho, um traço que aumentava e diminuía simetricamente. Só vale para quem já sabe o que è um helicóptero: quem nunca viu uma hélice em rotação descreverá apenas um segmento de reta que muda de comprimento. Se a descrição for ouvida por alguém em busca de anúncios de helicóptero, talvez possa ser corretamente interpretada. Este é o papel do cientista, inclusive na ISS, transformar o saber de senso comum. Ser capaz de avançar a ponto de concluir que há excesso de automóveis, ou falta de transporte coletivo, é outra história.

Duas obras, produzidas com intençōes e em épocas distintas, relacionadas com o funcionamento dos serviços de saúde, auxiliam na concretização destas idéias. Ambas aludem a esta interpretação "em segunda mão": cientistas interpretando o que foi visto e descrito por outros. Refiro-me a "La salud por el pueblo" (NEWELL, 1975) e a "From Research to Decision Making" (WHO, 1991). Publicadas pela Organização Mundial de Saúde, são para mim dois bons exemplos de "pesca de lambaris". Apenas a última, prefaciada por Yvo Nuyens, está inserida na nova linha de ISS preconizada pela OMS. Aliás, a história e a literatura estão fartas de utilizar o mesmo método. Na anedota, nunca 
concluída, em que Sancho Pança narrava a seu mestre o episódio do pastor de cabras Lope Ruiz perseguido pela Torralba, rica filha de um fazendeiro, ao ser indagado se a conhecera pessoalmente, respondeu candidamente: "eu a vi de ouvidos". É curioso notar que a história não é concluída porque Don Quixote se nega a aceitar a maneira como seu fiel escudeiro insiste em quantificar 300 cabras que vão sendo conduzidas, uma a uma, por um barqueiro através do Guaudiana, da Extremadura para o reino de Portugal. Nem sempre os mestres estão dispostos a aceitar as interpretações dos vassalos! Sancho não fica nada a dever ao grande Caspar Barlaeus que, apesar de nunca ter pisado solo brasileiro, contratado por Mauricio de Nassau para celebrar seus feitos, foi capaz de perpetrar a mais bela obra sobre a ocupação holandesa no período colonial, no século XVII*. Nessa obra, informado da imensa dissolução dos costumes, saiu-se com uma frase em latim no original: "ultra aequinoctiu num pecavit", traduzida por Chico Buarque, passados mais de três séculos, por "não existe pecado do lado de baixo do equador".

\section{UM FINAL FELIZ?}

Não considero banal a questão dos universais. Em algumas áreas, de maior amadurecimento epistemológico, chegou-se a um certo consenso. A pesquisa experimental em Física ou Química, observados os rigorosos preceitos de isolamento do sistema em estudo, conduz a resultados considerados válidos universalmente. Já o mesmo não é tão absolutamente certo na pesquisa Biológica, pelo menos não o será na Biomédica. É óbvia a determinação social da distribuição de endemias, como a doença de Chagas ou AIDS. O que não é tão óbvio é a determinação social das variantes antigênicas do T. cruzi ou do vírus

\footnotetext{
*Barlaeus (1647) [História dos feitos recentes praticados durante oito anos no Brasil e noutras partes, sob o governo do ilustríssimo João Maurício, Conde de Nassau. Tradução para o português, Claudio Brandão, Edição MEC, 1940].
} 
HIV. Porém, dependendo da via de transmissão, o agente pode ter, e geralmente tem, suas características antigênicas alteradas. Diversas hipóteses, em ambos os casos, associam patogenicidade e história natural da doença ao tipo de cepa do patógeno envolvido no processo. Um possível universal, a evolução da doença no homem vai para o espaço nestes casos. Outras vezes, o próprio arcabouço metodológico, especialmente no polo técnico, está determinado socialmente. Penso na Bioquímica e especialmente na Fisiologia. Mas também na Epidemiologia, um dos pilares da moderna Saúde Pública. Por razões distintas.

No caso das Biomédicas, os modelos experimentais dependem por exemplo do grau de desenvolvimento dos Biotérios. Camundongos, ratos, cobaias, cães e outros animais com "pedigree" e livres de germes são essenciais para a padronização dos experimentos. Hoje o biotério é uma verdadeira indústria com distribuição de matrizes que darão origem a colônias de características definidas, dentro de determinadas condições de cativeiro. Muitas revistas de circulação internacional e rigorosa crítica editorial rejeitam trabalhos científicos de Fisiologia ou Farmacologia que não tenham sido realizados usando no modelo experimental animais padronizados. Os estudos sobre diabetes experimental no rato foram revolucionados quando o brasileiro Renato Migliorini (de Ribeirão Preto) mostrou como se devia fazer a pancreatectomia total nesse animal. No estudo farmacológico da dor, a anestesia leve do cão, com registro vocal dos gemidos, só é possível onde não atuar uma agressiva corrente social de proteção dos animais de laboratório.

No caso da epidemiologia, valendo para toda Saúde Pública, aí incluída a ISS, a questão não é tão simples. Valem, claro, condições semelhantes às enunciadas para as Biomédicas. Testar, por exemplo a eficácia (fase 3) de uma vacina contra HIVIAIDS exige um preparo prévio tanto do grupo de voluntários quanto da população geral. Em alguns lugares será impossivel, em outros não 
serão impostos constrangimentos a sua aplicação em prisioneiros, por exemplo. Mas não é este o principal problema, reconhecivel em todos os campos, porém mais importante nas investigações que trabalham coletivos. Se, ao nivel individual, é discutível, no coletivo não há como negar a determinação social. Em qualquer disciplina o campo epistêmico luta por estabelecer ruptura entre o conhecimento científico e o conhecimento vulgar, de senso comum. Como assinalam BRUYNE, et. al (1982) a proximidade epistêmica imediata é a área disciplinar do pesquisador, com sua tradição e seu consenso intersubjetivo momentâneo. Também se dá a importação por migração do arsenal metodológico de disciplinas afins. Ocorre que esta migração de disciplinas afins em qualidade e profundidade depende, ao menos, da época e do lugar. Quando tratamos de coletivos, por exemplo nos estudos de Saúde Pública, estamos fatalmente impregnados do processo de determinação social. A disciplina que migra para ajudar o investigador em Saúde Pública não terá o mesmo referencial metodológico em todos os lugares. $\dot{E}$ diferente, por exemplo, nos E.U.A. e nos paises da América Latina onde, em particular, o referencial teórico da Epidemiologia Social está profundamente impregnado pela dialética marxista. Existem críticas, no meu entender exageradas, sobre o largo uso da simplificação representada pelo livro de Marta HARNECKER (1989) muito difundido na América Latina e chamado, pelos detratores, "vulgata marxista". Foi um momento do desenvolvimento da Epidemiologia em que muitos de nós fomos vítimas de um esforço quase ingênuo de operacionalização do conceito de classe social. Confesso que me incluo entre os que cometeram este "delito metodológico" (CARVALHEIRO, 1983), mas não tenho porque envergonharme dele. Até mesmo por ter tido a prudência de explicitar que se tratava de uma aproximação grosseira: operacionalização geográfica do conceito de classe social. Isto aponta para a outra variação do arsenal metodológico: o tempo. No caso do Brasil, no campo da Epidemiologia, existe hoje um importante grupo, ligado à Comissão de Epidemiologia da Abrasco, que se esmera em esquadrinhar os 
fundamentos teóricos da disciplina. Os autores citados pelos "jovens turcos" brasileiros da Epidemiologia compõem um elenco completamente distinto do que encontramos nas nossas publicações, por exemplo, da década passada. E não faz tanto tempo! Neste artigo, mesmo, adoto duas referências centrais que certamente serão consideradas datadas: BAILEY (1977) e BRUYNE et al (1982). Aventuro-me, muito discretamente, a afirmar que me vali da leitura de obra mais atual: SAMAJA (1995).

Diante desta confessada dificuldade no âmbito estrito dos pesquisadores profissionais, o que dizer da ISS? Pensada como pesquisa sobre os serviços, feita pelos mesmos profissionais, não há diferença. Seremos inconseqüentes se exigirmos uma ordem unida epistemológica, não cabem mais patrulhamentos. $O$ debate é da essência da produção cientifica. $O$ que pensar da idéia de difundir a pesquisa pela rede de saúde? No meu entender, exatamente o mesmo que se pensa quando se aproveitam registros em prontuários para pesquisa clinica. Haverá distinções entre épocas, lugares e sobretudo, entre grupos de pesquisadores. $O$ que não quer dizer que se desaconselhe a elaboração de prontuários tão completos e corretamente preenchidos quanto for possivel.

Os campos dos valores (axiológico) e do conhecimento gerado pelo cotidiano (doxológico) impregnam a ISS. Devemos descartar o conhecimento gerado nestas condições? Definitivamente, não. A seleção dos problemas a investigar e sua objetivação, assim como o método de busca das respostas, não são monopólio dos cientistas. Lembro dois exemplos por mim presenciados. 0 primeiro foi numa visita ao Sistema Local de Saúde de Corinto, uma pequena cidade do litoral pacifico da Nicarágua, em 1988. Governava Daniel Ortega e o SILOS era dirigido por uma militante do CDS (Centro de Defensa Sandinista) local, auxiliar de enfermagem. Fui com uma médica do Ministério da Saúde e um companheiro equatoriano, Rodrigo Yepez, da Universidade de Quito. Ao nos 
mostrar, orgulhosa, os registros de mortalidade infantil, a responsável exibiu erros grosseiros de cálculo destes indicadores. Um olhar cúmplice e um leve sorriso irônico foi o que vi no rosto de Yepez (e que ele, certamente, viu no meu). Duraram pouco. Aprofundando o diálogo, qual não foi nossa surpresa ao verificar que o compromisso da militante com seu trabalho ia a ponto de saber onde, como e em que condições morrera cada uma das crianças. $O$ que, para nós, eram números no numerador do coeficiente para ela eram pequeninos seres humanos de carne e osso, pranteados pela família. Sabia mais: não só quantos tinham nascido vivos, também quantas gestantes estavam sendo acompanhadas e as datas prováveis dos partos. Aí estava o denominador! Uma metodologia que baseasse a colheita de dados nos coeficientes mal calculados fracassaria. Mas os elementos para uma resposta adequada estavam disponiveis, bastava procurá-los.

O outro exemplo é mais recente, de novembro de 1995. Ouvi, pelo rádio, uma entrevista entre o responsável pelo atendimento aos traumatizados no Pronto Socorro do Hospital das Clínica da FMUSP e o âncora do programa. Duas pessoas inteligentes, pelo que depreendi do diálogo. Com meu viés acadêmico formulei a hipótese que o diálogo trazia implícita: o uso obrigatório do cinto de segurança na cidade de São Paulo e rodovias próximas deveria ter reduzido os traumas graves e fatais. Uma variável de conturbação era representada pela abertura do mercado aos automóveis importados. Além dos cintos, apresentam ainda outros dispositivos de segurança, do tipo de balōes automaticamente inflados quando ocorrem trombadas. Em contraposição, sendo mais velozes, aumentam os riscos de choques violentos. O médico, num primeiro momento, indicou o inesperado aumento do número de traumatismos graves e fatais, na demanda do PS. Buscando explicações, lembraram a recente implantação do resgate pelos bombeiros de São Paulo, pela Dersa (Companhia Rodoviária Estadual) e pelo grupo de voluntários chamado "Anjos do Asfalto". Casos que antes eram fatais no local do acidente, em vista da atual remoção quase imediata, chegavam ainda com 
vida ao HC. Embora numericamente aumentassem os acidentados graves e as fatalidades no hospital, muitos que antes morriam na rua estavam sendo salvos. 0 médico lembrou-se que era responsável, também, pelo serviço aos acidentados da Dersa e, pelo menos em relação às rodovias, tinha números que mostravam que, nos últimos anos, aumentaram os acidentes.

Em ambos os casos, pessoas inteligentes e comprometidas foram capazes, sem usar o instrumental metodológico mais adequado, de tirar conclusōes que não diferem muito das que um grupo acadêmico extrairia dos dados disponíveis. Quando pensamos na ISS não podemos desprezar contribuições como essas. É claro que um nivel mais abstrato só será possivel com a participação de investigadores profissionais. Porém isto pode ser obviado pela composição em rede, incluindo serviços e academia, no esforço por definir problemas importantes e encontrar possiveis explicações que possam orientar as ações. Para isto servem e nem é por outra razão que se chamam serviços. Não é demais lembrar a observação de alerta, feita por OMRAN (1990) em artigo publicado em periódico da OMS: os bons exemplos de ISS, evitados os escolhos, como diz o autor, são geralmente demorados; as ações, ao contrário, são geralmente imediatas e assumidas pelos dirigentes dos serviços aproveitando o conhecimento acumulado. Que pode ter sido gerado por ISS anteriormente realizadas, ali mesmo ou em outro lugar.

Com a radicalização do processo de municipalização, à semelhança do que aconteceu na hanseniase, novos desafios são colocados. $O$ desaparecimento da "inteligência epidemiológica" com a desativação dos programas verticais é um fato e não serve a ninguém ignorá-lo. Discordar da proposta de ISS formulada por OMS/OPAS/IDRC, por suspeitar de suas origens, não é justificativa para a inércia. Estamos à espera de proposta inteligente e inovadora. Que poderá muito bem ser uma rede de núcleos de apoio à ISS realizada nos serviços. Não há demérito em 
hierarquizar os núcleos de apoio, da mesma maneira que se hierarquizam os serviços de saúde.

Voltamos ao início, à citação de BAILEY (1977) e, por seu intermécio, à idéia de Marx de que não basta a interpretação diferente do mundo, pelos cientistas. Importante é encontrar as alavancas da transformação. Parece, no caso da ISS, que elas têm como ponto de apoio a formação de equipes organizadas e desenvolvendo projetos de interesse social. Articuladas em rede cuja eficácia, já o dissemos, depende do tamanho da malha. O desafio maior é discutir efetividade (lambaris ou tubarões?) e eficiência (quanto custa a SPT?)

\section{REFERÊNCIAS BIBLIOGRÁFICAS:}

1. ABRASCO - Congresso Brasileiro de Saúde Coletiva, $3^{\circ}$., Porto Alegre, 1992. Programa e Resumos. Porto Alegre, 1992

2. ABRASCO - Congresso Brasileiro de Epidemiologia, 2., Belo Horizonte, 1992. Programa e Resumos. Belo Horizonte, 1992-A.

3. ABRASCO - Congresso Brasileiro de Saúde Coletiva, 4., Olinda, 1994. Programa e Resumos. Rio de Janeiro, 1994.

4. ABRASCO - Congresso Brasileiro de Epidemiologia, $3^{\circ}$. ., Salvador, 1995. Resumos. Rio de Janeiro, 1995.

5. ALMEIDA, E. S. Resumen de lo informe de Brasil. In: Memorial del Taller de Cocoyoc, México, 1984, p. 205-33.

6. APEZECHEA, H. Aspectos metodológicos da la Investigación de Servicios de Salud. In: Memorial de Taller de Cocoyoc, Morelos, México, 1984, p.95-119.

7. BAILEY, N. T. J. The mathematical approach to biology and medicine. John Wiley Sons, 1967, New York.

8. BAILEY, N. T. J. Mathematics, statistics, and systems for health. John Wiley Sons, 1977, New York. 
9. BARROS, F. C.: VAUGHAN, J. P.; VICTORA, C. G. Por que tantas cesáreas? Necessidade de maiores mudanças de politica no Brasil. Health Policy Plan 1 (1): 19-29, 1986.

10. BISS. El programa de Ciencias Sociales de INCLEN, comentário. BISS (2) 5-6, 1989.

11. BROWNLEE, A. Capacitación para el desarrollo de las Investigaciones sobre Sistemas de Salud: publicación de la serie de Capacitación para ISS del CIIS/OMS. BISS (8) 6-7, 1991.

12. BRUYNE, P.; HERMAN, J.; Schoutheete, M. Dinâmica da pesquisa em ciências sociais: os polos da prática metodológica. 2a. ed., Rio de Janeiro, Francisco Alves, 1982.

13. CALLON, M. Introduction in la science et ses réseaux: genèse et circulation des faits scientifiques. Paris, La Découverte/Unesco, 1989, p. 7-33.

14. CARDOSO, M. R. L. ; PUCCINI, P. T.; NOBUMOTO, C. Descentralização da investigação para o nivel local. São Paulo, Instituto de Saúde, 1990.

15. CARVALHEIRO, J. R. Levantamento de condições de saúde por entrevistas domiciliárias. Ribeirão Preto, 1975. [Tese de Livre Docência - Faculdade de Medicina de Ribeirão Preto da USP]

16. CARVALHEIRO, J. R. Processo migratório e disseminação de doenças. Rio de Janeiro, Textos de Apoio - Ciências Sociais 1, ABRASCO, 1983.

17. CARVALHEIRO, J. R. La investigación de necesidades de salud en relación con la prestación de servicios. In: Memorial del Taller de Cocoyoc, Morelos, 1984, p. 121-41.

18. CARVALHEIRO, J. R. La implantación del SUS en Brasil y los polos tecnologicos. [Apresentado à OPS, como produto de assessoria temporária, Washington, 1993.]

19. CHORNY, A.; DURÁN, L.; GOLDBAUM, M.; GONZÁLEZ, G.; ROSSI, S. Investigación y sistemas locales de salud. In: Paganini, J. M. \& Capote Mir, $\mathrm{R}$, ed. Los sistemas locales de salud: conceptos, metodos, experiencias. Washington, 1990, p. 450-54.(OPAS - Publ. Cient. n 519)

20. CONACYT. Investigación en senvicios de salud. Memoria del seminario realizado en Querétaro, México, 1979. 
21. CONCURD/ENSP Seminário Nacional de Avaliação e Perspectivas da Coordenação Nacional dos Cursos Descentralizados, $10^{\circ}$., Rio de Janeiro, 1991. A pespectiva institucional da rede de formação em saúde coletiva no Brasil, Rio de Janeiro, ENSP/FIOCRUZ, 1991.

22. CREPALDI, M. A. Hospitalização na infância: representações sociais da familia sobre a doença e a hospitalização de seus filhos em Unidade de Pediatria. Campinas, 1995.[Tese de Doutoramento - UNICAMP]

23. ESCOLA NACIONAL DE SAÚDE PÚBLICA. Ante proyecto para la realización de un curso de capacitación en investigación en sistemas de salud en los SILOS en Brasil. Rio de Janeiro, 1990.

24. ESCOLA NACIONAL DE SAÚDE PÚBLICA. Carta do Rio de Janeiro sobre a formação da Rede de Cooperação na Investigação em Sistemas e Serviços de Saúde no Cone Sul, Rio de Janeiro, 1994.

25. FRY, J. Profiles of disease: a study in the natural history of common diseases. London, E \& S Livingstone, 1966.

26. GARCIA, J. C. Historia de las instituiciones de investigación en salud en América Latina, 1880-1930. Educ. Med. Salud, 15: 71-88, 1981.

27. GOMES COVA, D. ; ALMEIDA, E. S.; VARGAS, H. Resultados generales. In: Memorial del Taller de Cocoyoc, Morelos, México, 1984, p. 41-94.

28. HARNECKER, M. Los conceptos elementales del materialismo histórico. $57^{\mathrm{a}}$ ed., México, Siglo XXI Ed., 1989.

29. INSTITUTO NACIONAL DE SALUD PUBLICA. Portafolios ejecutivos para la toma de decisiones. Cuernavaca, Morelos, México, 1991.

30. LALONDE, M. A new perspective on the health of Canadians, a working document. Ottawa, Information Canada, 1974.

31. LAW, J. Le laboratoire et ses réseaux. In: CALLON, M., ed. La science et ses réseaux: genèse et circulation des faits scientifiques. Paris, La Découverte/Unesco, 1989, p. 117-148.

32. LOBO, E. Resultados preliminares da Convocatória da Rede de ISS para o Cone Sul (informação pessoal). 
33. NAVARRO, V. Consideraciones críticas sobre la antologia de ISS de la OPS, Washington, 1992.

34. NEWELL, K. W. ed. La salud por el pueblo. Ginebra, OMS, 1975.

35. NORONHA, M. \& GAWRYSZEWSKI. Seminário sobre Investigação em Sistemas e Serviços de Saúde no Cone Sul: estratégias para a construção de uma Rede de Cooperação; Relatório Final. Rio de Janeiro, ENSP, 1994.

36. NUYENS, Y. Adiestramiento para apoyar el desarrollo de la Investigación de Sistemas de Salud: uma iniciativa conjunta de IDRC, la OPS y la OMS. BISS (3), 5-11, 1989.

37. OMRAM, A. R. Investigación sobre sistemas de salud: métodos y escollos. Foro Mundial Salud, 11: 288-94, 1990.

38. ORGANIZACIÓN PANAMERICANA DE LA SALUD. Taller sobre investigación en los sistemas de salud, aplicada a los Programas de Control de la Lepra; Programa, Washington, 1992.

39. ORGANIZACIÓN PANAMERICANA DE LA SALUD. Princípios de epidemiologia para el control de enfermedades. Washington, Programa Ampliado de Libros de Texto de la OPS, 6 vis., 1979.

40. ORGANIZACIÓN PANAMERICANA DE LA SALUD. Investigación de servicios de salud; informe preliminar de Reunión sobre Red de Apoyo a la Investigación de Servicios de Salud (RAISS). Washington, 1987.

41. ORGANIZACIÓN PANAMERICANA DE LA SALUD. Investigaciones sobre servicios de salud: una antologia. Washington, 1992.(OPS - Publicación Científica $n^{\circ}$. 534).

42. OSUNA, L. J. Presentación del Seminário. Memorial de Taller de Cocoyoc, Morelos, México, 1984, p. 29-39.

43. REDE. Convocatória de investigação em serviços de saúde para Argentina, Brasil, Paraguai e Uruguai. Programa de Pequenos Financiamentos, IDRC e FIOCRUZ, 1995. [folheto de divulgação].

44. SAMAJA, J. Epistemologia y metodologia: elementos para una teoria de la investigación científica. $3^{\text {a }}$ ed., Buenos Aires, Eudeba, 1995. 
45. SONIS, A. La investigación de servicios de salud: problemas actuales. In: Paganini, J. M. \& Capote Mir, R., ed. Los sistemas locales de salud: conceptos, metodos e experiencias. Washington, 1990, p. 443-49. (OPS Publicación Científica $n^{\circ}$. 519)

46. TESTA, M. Pensar em saúde. Porto Alegre, Artes Médicas/Abrasco., 1992.

47. TESTA, M. Opinión sobre la propuesta de un programa de apoyo a la Investigación sobre Sistemas y Servicios de Salud, formulada por la ENSP y el Instituto de Saúde. 1994.

48. UNDERWOOD, E. A. Hippocrates. In: Encyclopaedia Britannica, 15th. Ed. Micropaedia, 1992, V. 5, p. 939.

49. UTMB Health Systems Research (HSR) in selected Latin American and Caribbean Countries. PAHONHO-UTMB Workshop, Galveston, 1992.

50. VIEIRA PINTO, A. Ciência e existência: problemas filosóficos da pesquisa científica. Rio de Janeiro, Paz e Terra, 1979.

51. VON STADEN, H. Don des dieux ou responsabilité des hommes? La Recherche (Suppl 281), p. 10-11, 1995.

52. WORLD HEALTH ORGANIZATION. AIma Ata Declaration: Intemational Conference on Primary Health Care, Alma Ata, URRS. Geneva, 1978.

53. WORLD HEALTH ORGANIZATION. Health systems research; background document. Geneva, 1990. (Technical Discussions/3)

54. WORLD HEALTH ORGANIZATION. Form research to decision making. Geneva, 1991. (WHO/SHS/HSR - 91.2)

55. YAZZLE ROCHA, J. S. ; ORTIZ, P. B.; TAI FUNG, Y. A incidência de cesáreas e a remuneração da assistência prestada durante o parto. Cad. de Saúde Pública, 1: 457-66, 1985.

56. YEPEZ, F. J. La investigación de servicios de salud. In: Memorial del Taller de Cocoyoc, Morelos, México, 1984, p. 143-151. 